International Journal of Advances in Pharmacy and Biotechnology

Vol.2, Issue-2, 2016, 6-14

Research Article

Open Access

I J A P B

ISSN: 2454-8375

\title{
ENHANCEMENT OF SOLUBILITY OF CANDESARTAN CILEXETIL BY SOLID DISPERSION METHOD
}

\author{
M. Gayatri Devi*, Siva Krishna, Sai Lakshmi, Sai Ram and P. Uma Devi \\ Viswanadha Institute of Pharmaceutical Sciences, Visakhapatnam, Andhra Pradesh, India. \\ *Corresponding author e-mail: gayatri.minnu@gmail.com
}

\begin{abstract}
:
Candesartan cilexetil has low bioavailability (16\%) and thus presents a challenge in formulating a suitable dosage form. To improve the aqueous solubility, solid dispersion formulation of candesartan cilexetil was prepared by solvent evaporation method utilizing skimmed milk powder as carrier. Five different formulations were prepared with different ratios of drug:carrier and the corresponding physical mixtures were prepared. The formulations were characterized for solubility parameters, drug release studies and drug-polymer interactions by using phase solubility studies, dissolution studies, FTIR spectrum and UV overlay spectra. Pure drug showed around $16.2 \%$ dissolution over a period of 60 minutes. Among all the formulations, F4 [(Candesartan cilexetil : skimmed milk Powder (1:7)] was found to be best of all the trails showing fast drug release up to $87.66 \%$. These results suggest that solid dispersion of Candesartan cilexetil using skimmed milk as carrier is a promising approach for oral delivery of Candesartan cilexetil.
\end{abstract}

Key words: Candesartan cilexetil, skimmed milk powder, solvent evaporation method.

\section{INTRODUCTION:}

Oral drug delivery is the simplest and easiest way of administering drugs. Because of the greater stability, smaller bulk, accurate dosage and easy production, solid oral dosages forms have many advantages over other types of oral dosage forms. Therefore, most of the new chemical entities (NCE) under development these days are intended to be used as a solid dosage form that originate an effective and reproducible in vivo plasma concentration after oral administration 1. In drug discovery, about $40 \%$ of new drug candidates display low solubility in water, which leads to poor bioavailability, high intrasubject or intersubject variability and lack of dose proportionality ${ }^{2}$. The aqueous solubility is a major indicator for the solubility in the intestinal fluids and its potential contribution to bioavailability issues. There are many approaches to increase solubility, such use of surfactants, complexation, polymorphism, salt formation, size reduction and emulsification ${ }^{3}$.

The concept of solid dispersion (SD) is defined the term solid dispersion as "a dispersion of one or more active ingredients in an inert carrier or matrix of solid state prepared by melting (fusion), solvent or melting solvent method"4. The concept offers many advantages, such as increased drug wettability, higher degree of porosity, no use of toxic constituents, flexibility of formulation and increased solubility and dissolution rate of the drug5. It is particularly advantageous for Bio-pharmaceutical classification system class 2 drugs.

Candesartan cilexetil is a drug used for treating high blood pressure (hypertension). 
It is in a class of drugs called angiotensin receptor blockers (ARBs). It has bioavailability of $90 \%$ and biological half life 9 hrs $^{6}$. Candesartan cilexetil bioavailability can be improved by developing a method simultaneously reducing the particle size and converting the drug to an amorphous state. Solid dispersion technology utilizes these techniques for improved performance ${ }^{6}$. Ankush Choudhary et al., have formulated Solid dispersion of atorvastatin using mannitol, PEG 4000 and PVP-k307. No attempt has been made to using skimmed milk as the carrier in the Candesartan cilexetil formulation. In the present work, solid dispersions of Candesartan cilexetil were prepared using skimmed milk as carrier. The skimmed milk is a colloidal suspension of casein micelles, globular proteins and lipoprotein particles. The principle ingredient casein acts as detergent molecule with surfactant property. The functional properties of skimmed milk powder are emulsifying agent, foaming agent, browning agent and thickening agent ${ }^{8}$. The Candesartan cilexetil SD was evaluated for solubility and dissolution rate. Different ratios of drug and carrier were used in the formulation. Simple physical mixtures(PM) of the drug with hydrophilic polymers increased the solubility of drug to some extent but formulation of solid dispersions by solvent evaporation method further improved the dissolution rate of the drug9. Candesartan cilexetil was identified by Infrared (IR) spectroscopy and Ultra violet (UV) spectroscopy determination.

\section{MATERIALS AND METHODS}

\section{Materials}

Skimmed milk powder was purchased from Mother Diary (Punjab India). All other solvents and reagents were of analytical grade.

www.ijapbjournal.com

\section{Preparation of SD}

Different Solid dispersions with different ratios of drug and carrier (skimmed milk powder) (1:1), (1:3), (1:5), (1:7), and (1:9) \% $\mathrm{w} / \mathrm{w}$ were prepared using by following solvent evaporation method, methanol as solvent. Required quantities of drug and polymer were dissolved in methanol to get a clear solution. Solvent was removed by continuous trituration which was carried out until a dry mass was obtained. This was further dried at $50^{\circ} \mathrm{C}$ for $4 \mathrm{hrs}$ in an oven. The product was powdered in a mortar, sieved through 60 mesh screen ${ }^{10}$.

\section{Preparation of PM}

Required amounts of Candesartan cilexetil and the carrier (skimmed milk powder) in the ratios of $1: 1,1: 3,1: 5,1: 7$ and 1:9 \% w/w (drug:carrier) were thoroughly mixed in a mortar and pestle in order to obtain a homogenous mixture. The resulting mixture was passed through 60 mesh sieve. The powder was stored in a screw cap vial at room temperature until further use ${ }^{\mathbf{1 1}}$.

\section{Estimation of drug content:}

The PM and SD equivalent to $10 \mathrm{mg}$ of Candesartan cilexetil were dissolved separately in $10 \mathrm{ml}$ of $0.2 \mathrm{~N}$ phosphate buffer $(\mathrm{pH}$ 6.8). The solution was filtered and further diluted as per requirment. The samples were filtered through a $0.45 \mu \mathrm{m}$ membrane filter and the drug content was determined spectrophotometrically at 255 $\mathrm{nm}$. The blank formulation was treated in the same manner as the Candesartan cilexetil formulations and used as a blank to minimize the interference of protein in the skimmed milk powder ${ }^{12}$.

\section{Saturation solubility studies of pure drug:}

Saturation solubility studies were conducted according to the method reported by Hecq et $a{ }^{14}$. Pure Candesartan cilexetil, was placed in 
a flask with glass stopper containing distilled water, phosphate buffer ( $\mathrm{pH}$ 6.8) and phosphate buffer ( $\mathrm{pH}$ 6.5). The samples were placed on a shaker, agitated for $48 \mathrm{hrs}$ at $37 \pm 0.5^{\circ} \mathrm{C}$ until equilibrium was achieved and the aliquots were filtered through $0.45 \mu \mathrm{m}$ filter. The filtered samples were diluted and assayed using a UV-visible spectrophotometer against a blank prepared ${ }^{\mathbf{1 3}, \mathbf{1 4}}$.

\section{Dissolution studies}

The in-vitro dissolution study was performed in a USP Type II Dissolution rate test apparatus (Electrolab, India) using $900 \mathrm{ml}$ of $0.2 \mathrm{~N}$ phosphate buffer $(\mathrm{pH} 6.8)$ at $355 \mathrm{~nm}$, with gentle stirring for $30 \mathrm{~min}$. Pure candesartan cilexetil or its equivalent of SD or PM was sprinkled into the dissolution flask. At predetermined time intervals, samples o the dissolution medium were withdrawn, filtered through amillipore membrane of 0.45 $\mu \mathrm{m}$ pore diameter and analysed spectrophotometrically against a blank formulation ${ }^{15}$.

\section{Characterization of solid dispersions:}

Fourier transform infrared (FTIR) spectroscopy was employed to characterize the possible interactions between the drug and the carrier in the solid state by the conventional $\mathrm{KBr}$ pellet method. The spectra were scanned over a frequency range 4000$400 \mathrm{~cm}^{-1}[16]$.

\section{RESULTS AND DISCUSSION}

Calibration curve: A stock solution of Candesartan cilexetil was prepared by dissolving drug in few $\mathrm{ml}$ of methanol and the final volume was made up to the mark using $0.2 \mathrm{~N}$ phosphate buffer. A series of standard solutions were prepared from the stock solution whose concentrations ranged from (10-90 $\mathrm{mcg} / \mathrm{ml})$. Using a UV-Vis spectrophotometer, calibration curve was obtained by reading corresponding absorbance values at $255 \mathrm{~nm}$.

The linear regression equation obtained was used for calculation of drug concentration in further study. The correlation coefficient was found to be 0.999 .

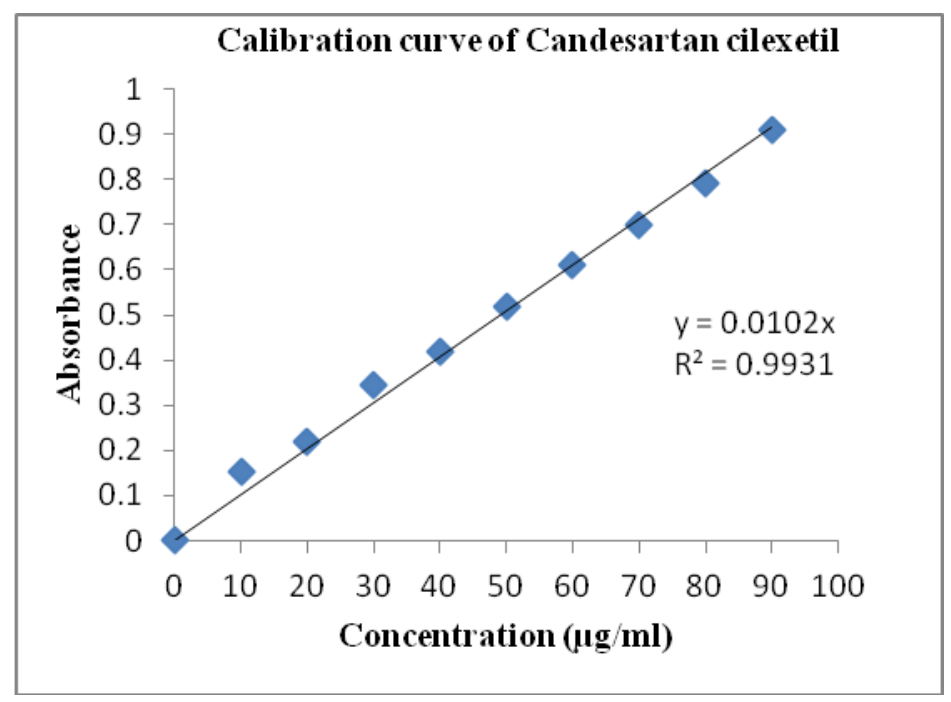

Fig. 1: Calibration curve of Candesartan cilexetil 
Table 1: Percent drug release vs time data of pure drug and formulations prepared by solvent evaporation

\begin{tabular}{ccccccc}
\hline \multirow{7}{*}{$\begin{array}{c}\text { Time } \\
\text { (min) }\end{array}$} & Drug & \begin{tabular}{c} 
SKMP \\
\cline { 2 - 7 }
\end{tabular} & SKMP & SKMP & SKMP & SKMP \\
& & $\mathbf{( 1 : 3 )}$ & $\mathbf{( 1 : 5 )}$ & $\mathbf{( 1 : 7 )}$ & $\mathbf{( 1 : 9 )}$ \\
\hline 5 & 0.8 & 17.91 & 18.18 & 17.82 & 17.19 & 18.99 \\
10 & 3.6 & 27.09 & 32.94 & 31.50 & 30.69 & 33.69 \\
15 & 5.4 & 34.20 & 43.11 & 42.30 & 45.54 & 44.10 \\
30 & 7.6 & 36.90 & 44.37 & 47.70 & 67.77 & 63.09 \\
45 & 11.7 & 54.90 & 49.23 & 60.30 & 78.66 & 71.10 \\
60 & 16.2 & 61.20 & 64.80 & 67.50 & 87.66 & 76.50 \\
\hline
\end{tabular}

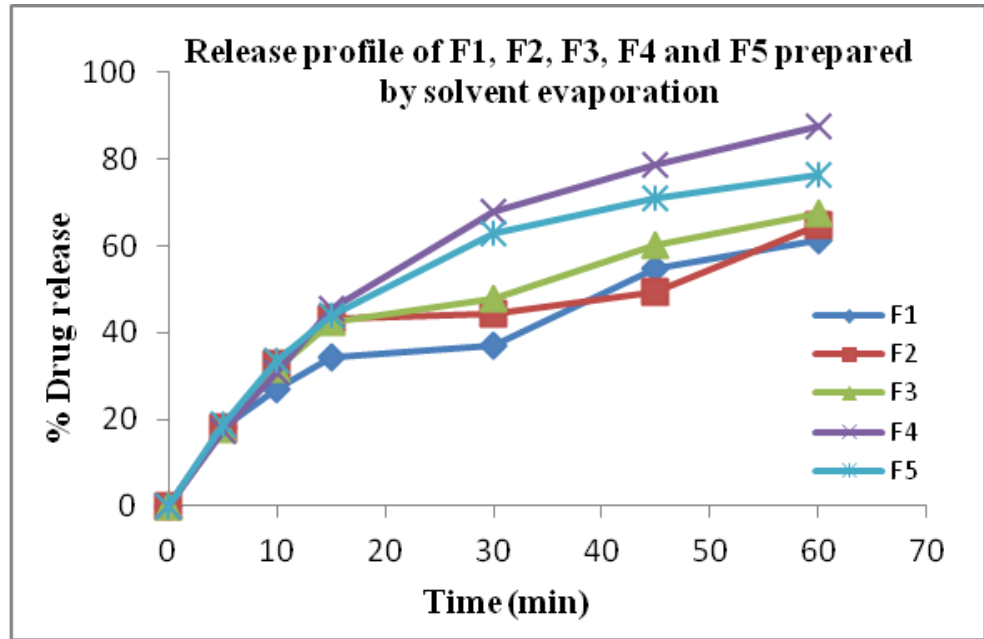

Fig. 2: Dissolution profile of Candesartan cilexetil formulations by solvent evaporation

Saturation solubility studies and pH solubility profile of pure drug:

Candesartan cilexetil showed a solubility of $0.142 \mathrm{mg} / \mathrm{ml}$ in distilled water, $0.112 \mathrm{mg} / \mathrm{ml}$ in $6.5 \mathrm{pH}$ phosphate buffer and $0.142 \mathrm{mg} / \mathrm{ml}$ in $6.8 \mathrm{pH}$ phosphate buffer.

\section{In-vitro dissolution studies:}

According to the results obtained with dissolution studies, all the solid dispersions exhibited higher rate of dissolution than the pure drug. This might be due to the change in the state of the drug from crystalline to amorphous, reduction of particle size increase in wettability and prevention of aggregation of the drug particles by carriers. Simple physical mixing of the drug with the hydrophilic polymers increased the solubility of drug to some extent but formulation of solid dispersions by solvent evaporation method further improved the dissolution rate of the drug. Pure drug showed around $16.2 \%$ dissolution over a period of 60 minutes, while its solid dispersions enhanced the dissolution rate up to $87.66 \%$. Formulation F4 Candesartan cilexetil: skimmed milk powder at a ratio 1:7 prepared by solvent evaporation technique showed highest dissolution rate. 
Table 2: Percent drug release vs time data of pure drug and formulations prepared by physical mixing

\begin{tabular}{ccccccc}
\hline \multirow{7}{*}{$\begin{array}{c}\text { TIME } \\
\text { (min) }\end{array}$} & Drug & $\begin{array}{c}\text { SKMP } \\
\text { (1:1) }\end{array}$ & $\begin{array}{c}\text { SKMP } \\
\mathbf{( 1 : 3 )}\end{array}$ & $\begin{array}{c}\text { SKMP } \\
\mathbf{( 1 : 5 )}\end{array}$ & $\begin{array}{c}\text { SKMP } \\
(\mathbf{1 : 7 )}\end{array}$ & $\begin{array}{c}\text { SKMP } \\
\mathbf{( 1 : 9 )}\end{array}$ \\
\hline 5 & 0.8 & 08.55 & 18.09 & 18.90 & 18.72 & 18.18 \\
10 & 3.6 & 10.35 & 28.44 & 28.53 & 34.20 & 32.76 \\
15 & 5.4 & 20.70 & 31.50 & 36.90 & 45.90 & 38.07 \\
30 & 7.6 & 31.50 & 41.40 & 45.00 & 58.50 & 47.34 \\
45 & 11.7 & 47.70 & 51.36 & 53.10 & 67.50 & 59.04 \\
60 & 16.2 & 58.50 & 63.09 & 66.60 & 81.90 & 72.00 \\
\hline
\end{tabular}

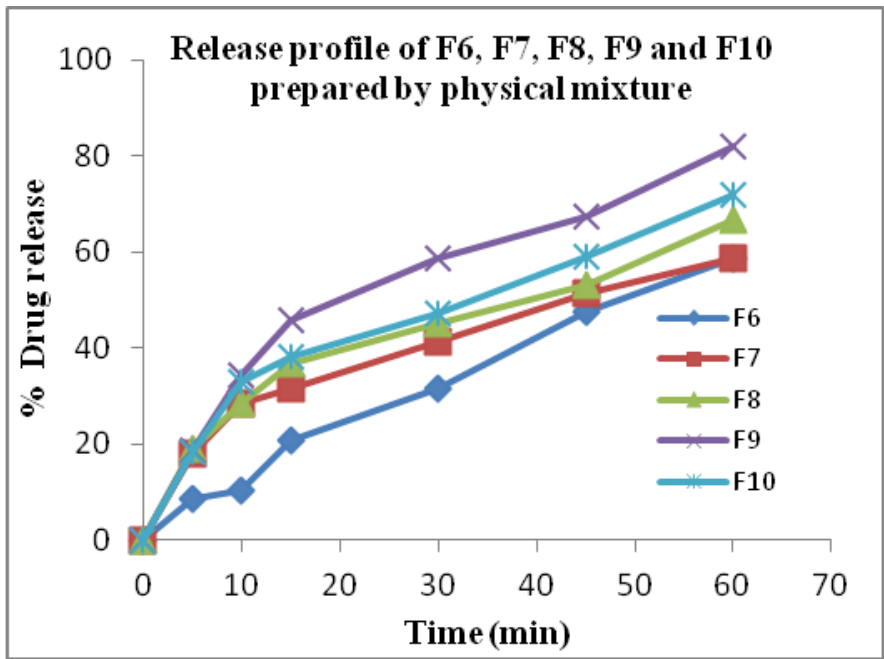

Fig. 3: Dissolution profile of prepared formulations by physical mixing

Drug-polymer compatibility study by Fourier Transform Infrared Spectroscopy

IR spectrum of Candesartan cilexetil was characterized by presence of peaks at $3061.36 \mathrm{~cm}^{-1}$ (N-H stretch), $2982.02 \mathrm{~cm}^{-1}$ (C$\mathrm{H}$ stretch), $1706.03 \mathrm{~cm}^{-1}$ (C=0 stretch) and $1611.90 \mathrm{~cm}^{-1}$ (C-N stretch). All the solid dispersions showed characteristic peaks of
Candesartan cilexetil and the skimmed milk powder. No significant shift in the characteristic peaks for the drug and carrier indicated no significant interaction between them in formulations. 


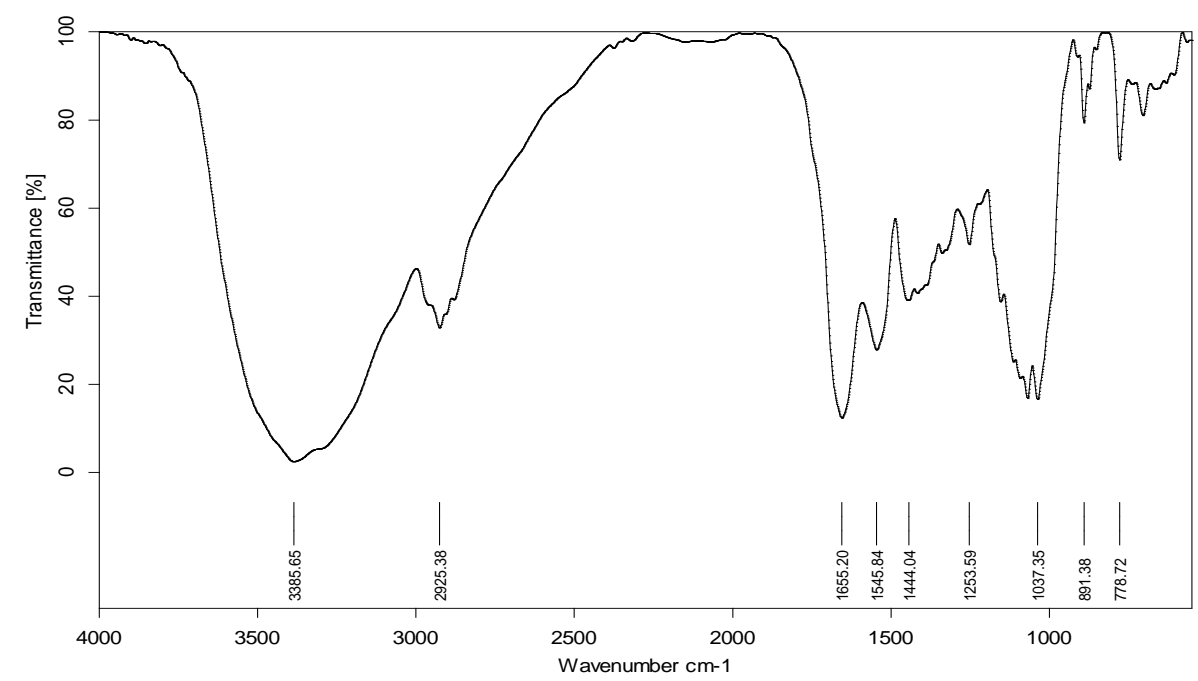

Fig. 4: FTIR spectrum of pure Drug

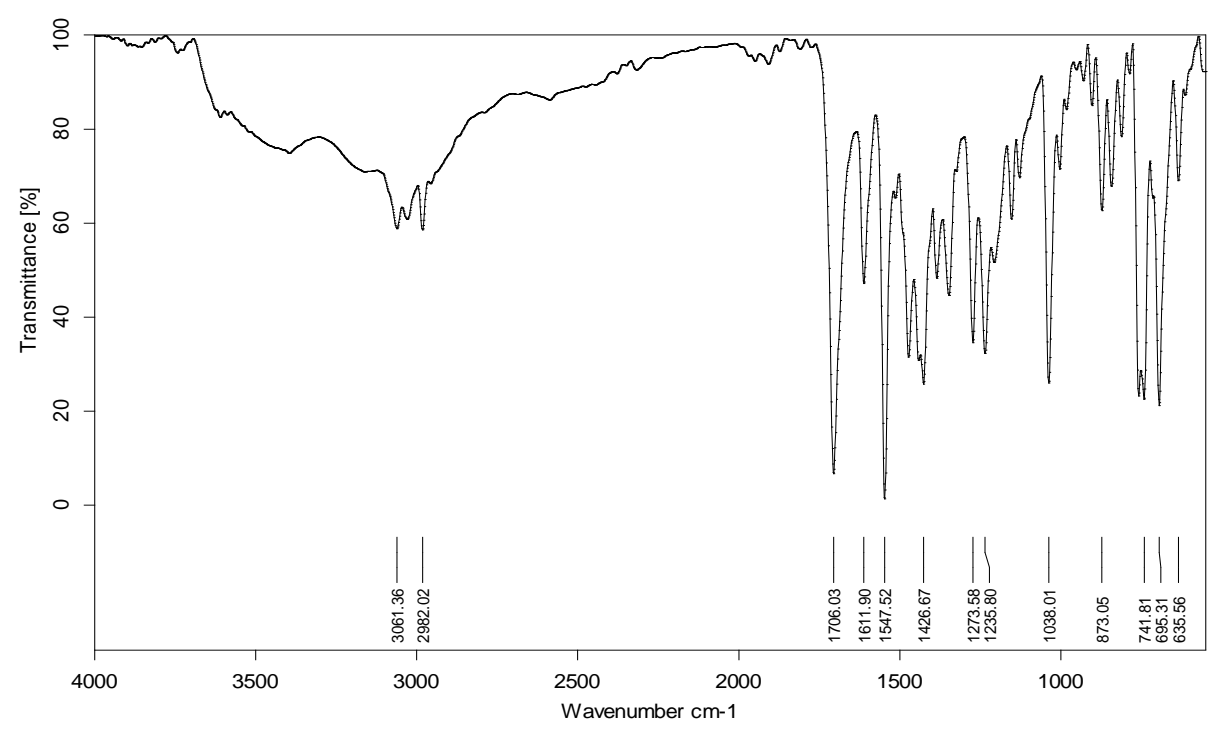

Fig. 5: FTIR spectrum of skimmed milk powder

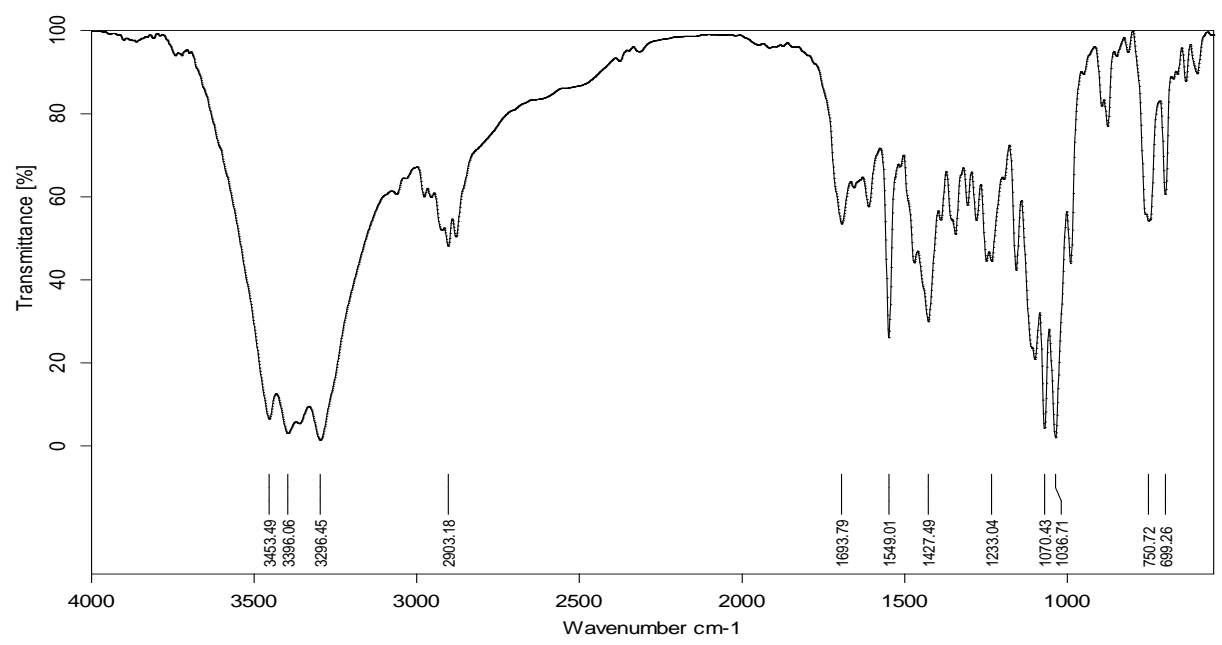

Fig. 6: FTIR spectrum of formulation, F4 


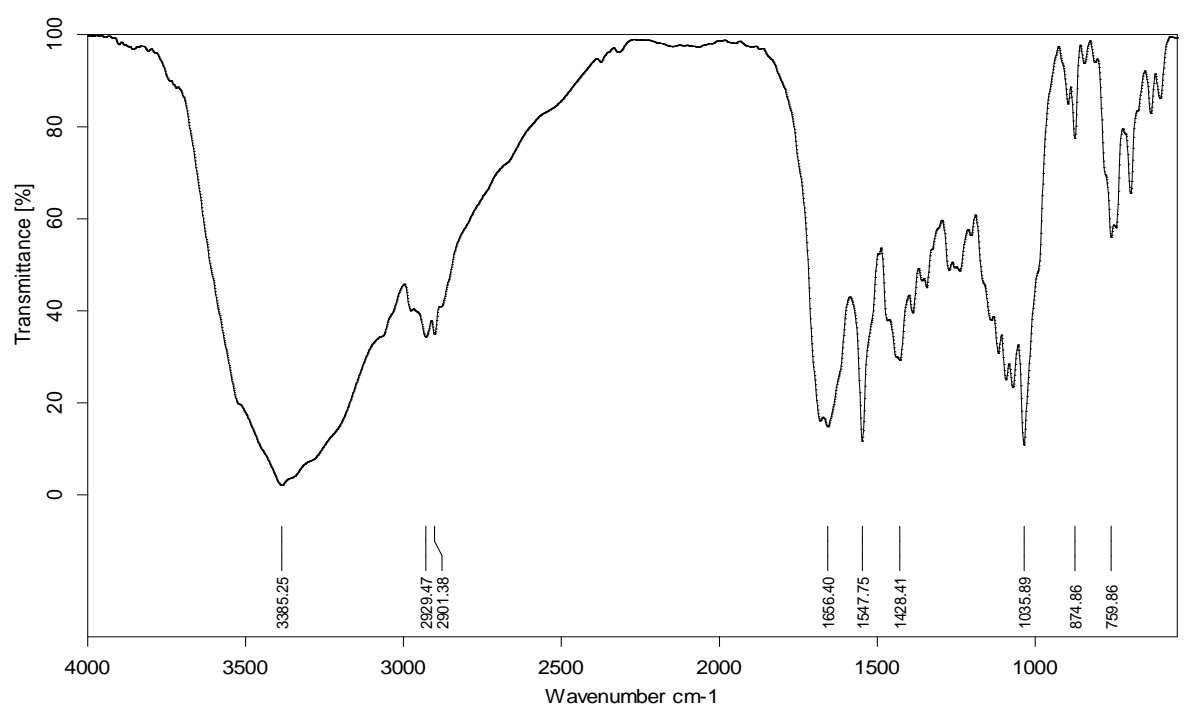

Fig. 6: FTIR spectrum of formulation, F4

\section{CONCLUSION}

- The order of drug release of Candesartan cilexetil with skimmed milk powder is as follows: F4> F9> F5 $>$ F10 $>$ F3 $>$ F8 $>$ F2 $>$ F7 $>$ F1 $>$ F 6

- All the formulations showed good release of drug. But the formulation F4 (Candesartan cilexetil : skimmed milk powder (1:7)) was found to be best of all the trails showing fast drug release among all the formulations.

- The drug polymer interactions were found to be absent from the results of FT-IR characterization.

- From these results, it was concluded that the solubility and dissolution rate of Candesartan cilexetil can be significantly increased by formulating the solid dispersions with skimmed milk powder with following solvent evaporation method.

- The approach is found to be economical and time saving.

\section{ACKNOWLEDGEMENT}

The authors are thankful to the management, principal and staff of Viswanadha Institute of Pharmaceutical Sciences for their support in conducting the present investigation.

\section{REFERENCES}

1. Teofilo V, Bruno S, Paulo C. Solid dispersions as strategy to improve oral bioavailability of poor water soluble drugs. Drug Discovery Today., 2007; 12:23-24.

2. Bo Tang, Gang Cheng, Jian-Chun Gu, CaiHong $\mathrm{Xu}$. Development of solid selfemulsifying drug delivery systems: preparation techniques and dosage forms. Drug Discovery Today., 2008; 13:606-612.

3. Choudhary A, Aggarwal G, Zakir F, Kumar V. Minireview: Journey of solid dispersion technique from bench tos cale. Int Res J Pharm., 2011; 2:46-51.

4. Craig DQM. The mechanisms of drug release from solid dispersions in watersoluble polymers. Int J Pharm., 2002; 231(2):131-144.

5. Bikiaris DN. Solid dispersions, part I: Recent evolutions and future opportunities in manufacturing methods for dissolution rate enhancement of poorly water-soluble drugs. Expert Opin Drug Deliv., 2011;8:1501-19. 
6. Asif Husain et al., A Review on Candesartan: Pharmacol Pharm J of Applied Pharm Sci., 2011; 01(10): 12-17.

7. Ankush choudhary and Geetha agarwal et al., Development and characterization of an atorvastatin solid dispersion formulation using skimmed milk for improved oral bioavailability, Acta Pharmaceutica Sinica B., 2012; 2(4): 421-428.

8. Neha sharm et al., Formulation and Evaluation of gastro retentive floating tablets containing cefpodoxime proxetil solid dispersions. Int J Current Pharm Res., 2012; 4(4): 0975-7066.

9. Yakugaku zasshi, Preparation and Evaluation of Solid Dispersion of Meloxicam with Skimmed Milk. The Pharmaceutical Society of Japan., 2006;126(2): 93-97.

10. Dhirendra K, Lewis S, Udupa N, Atin K. Solid dispersions: A Review. Pak J Pharm Sci., April 2009; 22(2): 234-246.

11. Vippagunta SR, , TallavajhalaS, GrantDJ Solid state characterization of nifedipine solid dispersions. Int $J$ Pharm., 2002; 236:111-23.

12. Venkates K Arunkumar N, Verma PRP, Rani C. In-vitro characterization of valsartan solid dispersions using skimmed milk powder a scarrier. Int $J$ Pharm Tech Res., 2009; 3: 431-7.

13. Vanden Mooter G, Wuyts M ,Blaton N, Busson R, Grobet P, Augustijns P et al., Physical stabilization of amorphous sketoco-nazole in solid dispersions with polyvinylpyrrolidone K25. Eur J Pharm Sci., 2001; 12: 261-9.

14. Hecq J, Deleers M, Fanara D, Vranckx H, Amighi K. Preparation and characterization of nano crystals for solubility and dissolution rate enhancement of nifedipine. Int J Pharm., 2005; 299: 167-77.
15. Indian Pharmacopoeiae., 2007;1: 179.

16. Cirri M, Mura P, Rabasco AM, Gines JM, Moyano JR, Gonzalez-Rodriguez ML. Characterization of ibuproxam binary and ternary dispersions with hydrophilic carriers. Drug Develop Ind Pharm., 2004; 30(1):65-74.

17. Anupama Kalia, Mayur Poddar. Solid dispersions: an approach towards enhancing dissolution rate. Int J Pharm Pharm Sci., 2011; 3(4): 9-19.

18. Arunachalam A, Karthikeyan M, Kishore Konam, Pottabathula hari Prasad, Sethuraman S, Ashutosh kumar S. Solid Dispersions: A Review. Current Pharm Res., 2010; 1(1):82-90.

19. Sanjoy KD, Sudipta R, Yuvaraja K, Jasmina K, Arunabha N. Solid dispersions: An approach to enhance the bioavailabilty of poorly watersoluble drugs. Int $J$ Pharmacol and Pharm Tech., 1(1):37-46.

20. Hamsaraj K, Vikram SS, Rayasa RM. Industrially feasible alternative approaches in the manufacture of solid dispersions: A Technical report. AAPS Pharm Sci Tech., 2006; 7(4): E1-E8.

21. Sameer singh, Raviraj SB, Lalit Y. A review on solid dispersion. Int J Pharm Health Sci., 2011; 2 (9): 1078-1095.

22. Ruchi T, Gaurav T, Birendra S, Awani KR. Solid dispersions : An overview to modify bioavailability of poorly water soluble drugs. Int J Pharm Tech Res., 2009; 1(4):1338-1349.

23. Chaturvedi A K, Amita V. Solubility enhancement of poorly water soluble drugs by solid dispersion. Int J Pharm Sci Res., 2012; 3(1): 26-34.

24. Patel TB, Patel LD. Formulation and development strategies for drugs insoluble in gastric fluid. International Res J Pharm., 2012; 3(1): 106-113. 
25. Anuj K, Sangram K S, Kumud P, Prithi P $\mathrm{S} \mathrm{K}$, Ajit S, Naveen P. Review on solubility enhancement techniques for hydrophobic drugs. Pharmacie globale Int J Comprehensive Pharm., 2011; 3 (03): 1-7.

26. Sharma DK, Joshi SB. Solubility enhancement strategies for poorly water soluble drugs in solid dispersions: A review. Asian J Pharm., 2007; 1(1): 9-19.

27. Meera CS, KB Sayed, Dr. Sawant SD. Review on various techniques of solubility enhancement of poorly soluble drugs with special emphasis on solid dispersion. J Pharm Res., 2010; 3(10): 2494-2501.
28. Damodharan N et al., Preparation and Evaluation of solid dispersion of Candesartan cilexetil. Journal of Pharm Res., 2012;5(1): 333-337

29. Ramya Krishna S. Formulation and invitro evaluation of oral disintegrating tablets containing solid dispersions of Candesartan Cilexetil. The Pharma Journal., 2014; 3(4).

30. Al-nuss raghad, El-zein hind. Enhancement of Candesartan Cilexetil dissolution rate by using different methods. Asian J Pharm Clin Res., 2015; 8(1): 320-326.

31. Ahmad Zaheer et al., Solubility enhancement of poorly water soluble drugs: A review, Int J Pharm Tech., 2011; 3(1): 807-823.

\section{How to cite this article:}

M. Gayatri Devi et. al., Enhancement of solubility of candesartan cilexetil by solid dispersion method. Int. J. Adv. Pharm. Biotech., 2016; 2(2): 6-14. 